\title{
Uma rua na favela e uma janela na cela: precariedades, doenças e mortes dentro e fora dos muros
}

\author{
Fábio Mallart (https://orcid.org/0000-0001-9033-030X)' \\ Instituto de Medicina Social, \\ Universidade do Estado do Rio de Janeiro (Uerj), Rio de Janeiro, RJ, Brasil. \\ Fábio Araújo (http://orcid.org/0000-0001-9248-8071)" \\ Universidade Federal do Rio de Janeiro (UFRJ), Rio de Janeiro, RJ, Brasil.
}

Recebido: 30.12 .20

Aprovado: 17.03 .21

\author{
I. Fábio Mallart \\ é mestre em \\ antropologia social e \\ doutor em sociologia \\ pela Universidade \\ de São Paulo (USP). \\ Atualmente, é \\ pesquisador de \\ pós-doutorado \\ pelo Instituto de \\ Medicina Social da \\ Universidade do \\ Estado do Rio de \\ Janeiro (bolsista \\ PNPD/Capes). \\ <fabiomallart@ \\ gmail.com> \\ II. Fábio Araújo é \\ doutor em sociologia \\ pela Universidade \\ Federal do Rio de \\ Janeiro (UFRJ) e \\ pesquisador da \\ Fiocruz. Ambos \\ os pesquisadores \\ são membros do \\ "GT Clacso Barrios, \\ familias y prisiones \\ en circuitos", sendo \\ que as reflexões aqui \\ propostas ressoam \\ nas questões \\ trabalhadas pelo GT. \\ <fabioaaraujoster@ \\ gmail.com>.
}

Abstract: Taking the debate over the relations of continuity between the inside and outside in prisons as a starting point, this text aims to reflect from a singular point of view about the link which connects prisons, favelas and the outskirts. In times of Covid-19, these links may be associated with the infrastructure and materiality of these places. Densely populated and poorly ventilated and lit areas, water rationing, or floods, open sewage, and accumulation of garbage are some features of structural precariousness that connect prisons and the city outskirts. Previous ethnographic studies, analyses of documents, and interviews show how precariousness is decisive in the prevalence of certain illnesses among black, poor, and peripheral populations and point to a differential distribution of illnesses and deaths.

Keywords: prisons, outskirts, pandemic, precariousness, deaths. 


\section{Introdução:}

\section{a prisão e suas extensões}

$\left\{\begin{array}{l}\text { o longo do século } X X \text {, diversos autores tomaram as instituições prisionais } \\ \text { como objeto de análise. De partida, vale lembrar que alguns dos trabalhos } \\ \text { que serviram de base aos estudos sobre as prisões centraram as suas refle- }\end{array}\right.$ xões do lado de dentro das muralhas (Clemmer, 1940; Sykes \& Messinger, 1960; Goffman, 1974). Dessa perspectiva, o cárcere emerge como uma espécie de realidade no vácuo, separada dos contextos e das forças que para além dos muros participam de sua configuração (Cunha, 2004). Com efeito, é o pressuposto de que a prisão figura como um mundo social à parte que caracterizou o campo dos estudos prisionais, como se a reclusão fosse uma espécie de intervalo social e cultural.

Ainda que esses trabalhos tenham pautado um vasto campo de estudos, é importante observar que outros autores do mesmo período já apontavam para as conexões entre o dentro e o fora, a começar por Rusche e Kirschheimer (2004), que, em 1939, sublinhavam que o cárcere funcionava como um fator de regulação do mercado de trabalho, abrindo e fechando as suas comportas de acordo com as variações dos ciclos econômicos.

Em 1975, com a publicação de Vigiar e punir, Foucault (1987) proporia novas bases para a compreensão das prisões. Longe de figurar como um mundo à parte, o cárcere emerge como "um revelador da sociedade" (Cunha, 2015: 186), afinal, as ponderações do autor dizem menos respeito à instituição prisional do que ao surgimento de novas tecnologias de poder, que conformariam uma sociedade disciplinar. Ademais, a força das muralhas não residiria em sua impermeabilidade material, mas nos múltiplos fios que as atravessam, na capilaridade que as abastece e as esvazia (Foucault, 2015a).

Embora haja trabalhos que ainda enfoquem o perímetro institucional - o problema não está em refletir sobre a dinâmica intramuros, mas em fazer da separação entre o dentro e o fora um pressuposto irrefletido -, nos últimos anos multiplicaram-se os estudos que abordam as conexões entre o interior e o exterior. Ao tematizar as relações que se estabelecem entre a prisão e o seu entorno, pode-se, por exemplo, analisar como os efeitos estigmatizantes do cárcere ressoam na vizinhança imediata (Combessie, 2002). Em outra chave, problematiza-se os impactos da reclusão para os familiares de presos e presas, justamente porque as suas vidas são afetadas pela detenção (Comfort, 2007). De outro prisma, constata-se que os nexos entre o intra e o extramuros são fundamentais para a própria prisão, afinal, é por meio de seus "vasos comunicantes" - cartas, celulares, familiares etc. - que a máquina 
carcerária se viabiliza (Godoi, 2017). Ademais, a potência dos fluxos que cortam as muralhas é digna de nota, visto que eles podem atravessar até mesmo fronteiras nacionais (Padovani, 2015; Bumachar, 2016).

A explosão da população carcerária ao longo das últimas décadas, processo que Garland (2001) chamou de encarceramento em massa, e Wacquant (2009), numa definição mais precisa, de hiperencarceramento concentrado, fomentou uma série de estudos que lançam luz sobre o imbricamento das prisões com determinadas regiões urbanas, tais como periferias e favelas brasileiras (Barbosa, 2005), guetos estadunidenses (Wacquant, 2007), townships sul-africanas (Waltorp \& Jensen, 2019), banlieues parisienses (Bony, 2015) ou bairros portugueses (Cunha, 2002) e camaroneses (Morelle, 2015) específicos - em suma, as áreas habitadas pelas populações mais pobres das cidades. Entre outras potencialidades, esses escritos ressaltam a concentração espacial do encarceramento, a incorporação dos bairros pela prisão - bem como da prisão pelos bairros - e a disseminação da experiência carcerária entre esses territórios e suas populações, delineando um continuum entre prisões-favelas-periferias.

É exatamente na extensão dessas relações de continuidade que este artigo se insere. Tendo em vista as precárias condições de existência às quais determinadas populações - negras, pobres e moradoras de periferias - são submetidas, pretende-se ampliar essas discussões. Em tempos de Covid-19, evidencia-se como esses nexos também podem ser pensados a partir das infraestruturas e das materialidades desses espaços ${ }^{1}$. Densidade populacional, locais pouco ventilados e mal iluminados, racionamento de água ou enchentes, solos contaminados, acúmulo de lixo e esgoto a céu aberto são só alguns dos traços que ligam prisões e periferias. São essas precariedades que nos auxiliam a compreender a prevalência de determinadas enfermidades - por exemplo, o novo coronavírus - que afetam diferencialmente tais populações, demonstrando o caráter desigual do adoecimento e da morte.

Nas linhas abaixo, realizamos três movimentos. Em primeiro lugar, a partir da descrição da dinâmica de funcionamento de uma cadeia subterrânea, no Rio de Janeiro, refletimos sobre as chamadas "mortes naturais". Superlotação, racionamento de água, alimentação de péssima qualidade e falta de serviços médicos são alguns dos fatores que nos ajudam a compreender como as prisões operam um massacre lento e silencioso, que ganhou força durante a pandemia. Em um segundo momento, tendo como ponto de partida um edifício subterrâneo, na favela da Rocinha, propomos uma espécie de reflexão em espelho, mostrando como algumas condições estruturais precárias, que fomentam a propagação do vírus, aproximam tais espaços. Como nas prisões, os índices de mortalidade em regiões periféricas, quando 
2. Sobre essas parcerias, as quais podem articular uma miríade de atores - coletivos e movimentos organizados, pesquisadores, familiares de presos e presas, defensores públicos, entre outros -, tal questão vem sendo discutida por uma ampla rede de pesquisadores, onde o desafio consiste em refletir sobre o estatuto desses saberes elaborados coletivamente, assim como sobre os nexos entre pesquisa e engajamentos sociopolíticos. São questões que giram em torno da construção de um campo epistêmico, que interfere na forma como formulamos os nossos problemas de pesquisa (Grupo de Pesquisa Cidade e Trabalho, 2020). comparados com outras áreas das cidades, revelam a distribuição diferencial das mortes. À guisa de conclusão, a partir das conexões entre territórios, precariedades infraestruturais, doenças e óbitos, argumentamos que a destruição, construção e manutenção de algumas infraestruturas compõem políticas de morte.

Na medida em que se trata de perscrutar relações de continuidade, as quais atravessam diferentes espaços, mobilizamos estratégias metodológicas variadas. Dados etnográficos de pesquisas que temos realizado durante os últimos anos, seja em unidades prisionais, seja em determinadas zonas periféricas de São Paulo e Rio de Janeiro. Sem desconsiderar a relevância das dinâmicas locais, esses estudos privilegiam a produção de uma etnografia transversal, focada nas ressonâncias entre distintos espaços urbanos (Mallart \& Rui, 2016; Mallart, 2019). Ademais, são pesquisas cujos relatos etnográficos se baseiam em descrições detalhadas dos lugares visitados - cores, cheiros, líquidos, cicatrizes, texturas, precariedades estruturais etc. -, conferindo materialidade a esses cenários. Nessa direção, posto que a análise sobre as condições estruturais do cárcere é central, utilizamos trechos de relatórios de inspeção elaborados pela Defensoria Pública do Rio de Janeiro (DPE/ RJ), no âmbito do programa de monitoramento do sistema penitenciário, assim como relatórios produzidos pelo Mecanismo Estadual de Prevenção e Combate à Tortura (MEPCT/RJ). Concentramo-nos, em especial, nos escritos que versam sobre o fornecimento de água potável, a qualidade e a quantidade da alimentação, as condições de celas, corredores e galerias, as dinâmicas dos banhos de sol, as enfermidades prevalentes na população carcerária e a superlotação. Por mais que o foco do presente texto esteja no Rio de Janeiro, com o objetivo de reforçar e alargar a discussão, referências pontuais a São Paulo, e mesmo ao contexto nacional, também serão feitas.

Fora dos muros, ainda que nos apoiemos em estudos etnográficos anteriores (Mallart, 2011; Araújo, 2017), em tempos de pandemia, período em que as circulações estão restritas, encontramos em médicos de saúde da família da favela da Rocinha uma parceria para refletir acerca das precariedades estruturais de tal território. Pela própria característica do trabalho desenvolvido por esses profissionais, com o foco comunitário e territorial, são eles que nos conduzem pelas moradias sem ventilação e luminosidade, assim como pelas vielas escuras e apertadas de uma das maiores favelas do país². São esses métodos combinados - pesquisa etnográfica, análise documental e realização de entrevistas - que permitem nos situar nem dentro e nem fora dos muros, mas nas dobras e continuidades. 


\section{A cadeia subterrânea: como matar naturalmente}

09 de junho de 2015, Presídio Ary Franco, Água Santa (RJ). A área destinada à custódia dos presos é bastante claustrofóbica em razão da inclinação do relevo e da falta de planejamento, o que dá a sensação de localizar-se no subterrâneo. A direção da unidade prisional informou que a capacidade total do estabelecimento é de 968 presos, no entanto, havia 2.063 internos na unidade na data da vistoria. As paredes, o teto e o chão, na medida em que se caminha em direção às celas, vão ganhando um aspecto cada vez mais imundo com infiltrações, vazamentos, insetos, sujeira e teias de aranha. $O$ acúmulo de lixo e as infiltrações tornam o ambiente além de sujo, muito úmido, o que é agravado pela superlotação. A iluminação comumente se dá através de "gambiarras" improvisadas pelos próprios internos, situação que oferece riscos tanto de choque elétrico quanto de incêndio pela fiação exposta. Dentro das celas observam-se canos quebrados, "bois" [banheiros] entupidos e água inundando parte das celas. A maioria dos detentos afirmaram nunca ter saído da cela para o banho de sol, alguns já ali há 2 (dois) ou 3 (três) meses. Os internos reclamaram muito da alimentação fornecida na unidade. Tanto no que diz respeito a qualidade, a quantidade e aos constantes atrasos no horário em que esta é servida. Uma reclamação comum nas unidades visitadas pelo Monitoramento Carcerário da Defensoria Pública é o rigoroso racionamento de água feito nas unidades. Entretanto, no Presídio Ary Franco, a distribuição da água parece não ser o problema, mas sim a qualidade desta. Muitos reclamam do gosto de ferrugem e por vezes do odor; alguns relataram que em determinados períodos a água traz muitas partículas não identificadas e que por isso improvisam uma espécie de filtro com garrafas plásticas e tecido. Os relatos indicam grande dificuldade ao acesso da assistência médica, segundo os presos, é preciso estar beirando a morte pra conseguir ir à enfermaria. O ambiente sujo e úmido das celas colabora para a proliferação de doenças, especialmente respiratórias como a tuberculose.

O fragmento acima, retirado de um relatório de inspeção produzido pela Defensoria Pública do Rio de Janeiro, longe de retratar a dinâmica de funcionamento de uma só prisão, espelha a realidade do sistema penitenciário brasileiro. Se, de uma perspectiva sincrônica, o excerto rebate nos outros estados da Federação, ao posicioná-lo na linha do tempo, nota-se que antes e depois de 2015 os traços que o constituem são perenes.

Em 2011, o Subcomitê de Prevenção da Tortura das Nações Unidas, ao adentrar nas dependências de tal presídio, já anotara que as celas eram escuras, sujas e infesta- 
3. Disponível em: $<$ https://extra.globo. com/noticias/rio/ especialista-alertapara-disseminacaode-sarampono-presidio-aryfranco-24306591. html>. Acesso em: 04 Ago. 2020.

\section{Disponível em:} <http://www.ensp. fiocruz.br/portalensp/informe/ site/materia/ detalhe/45983>. Acesso em: 06 Ago. 2020.

\section{Disponível em:} <https://noticias. uol.com.br/ cotidiano/ultimasnoticias/2017/08/14/ massacre-silenciosomortes-por-doencastrataveis-superammortes-violentas-nasprisoes-brasileiras. htm>. Acesso em: 06 Ago. 2020.

6. Disponível em: <https://www1. folha.uol.com.br/ cotidiano/2018/08/ rj-tem-1-mortede-preso-a-cada2-dias-e-orgaocita-doencas-empresidios.shtml. Acesso em: 05 ago. 2020.

7. Disponível em: <https://www.terra. com.br/noticias/ brasil/politica/ aumenta-numero-depresos-mortos-nascadeias-de-sao-paul o,686c29f999ecec05 7a7a6ab6318cd44bt ijmfezv.html. Acesso em: 05 Ago. 2020.

8. Disponível em: <https://oglobo. globo.com/ brasil/cadeia-de- das de baratas e outros insetos. À época, o sistema de esgoto dos pisos superiores vazava pelo teto e pelas paredes, afetando as celas inferiores. Na cadeia subterrânea, na qual, em 2015, a defensoria afirmou que a superlotação e a umidade fomentavam a proliferação de doenças respiratórias como a tuberculose, em 2011, tal como apurado pelo subcomitê, e descrito no relatório da defensoria, os detentos sofriam com as doenças de pele e do estômago. Em março de 2020, em pleno cenário de pandemia, a prisão possuía 17 casos suspeitos de sarampo ${ }^{3}$, doença com alto potencial de transmissibilidade, ainda mais em espaços superlotados e com pouca ventilação.

Nesse contexto, as mortes por doenças apontam para a existência de um massacre - lento, progressivo e silencioso. O caso do Rio de Janeiro, cuja taxa de mortalidade é a mais elevada do país (cinco vezes a média nacional) ${ }^{4}$, é paradigmático. Somente entre janeiro de 2015 e agosto de 2017, 517 presos e presas faleceram em virtude de distintas enfermidades 5 . Conforme dados da Defensoria Pública, elaborados a partir da análise dos laudos cadavéricos de 83 presos, que morreram entre 2014 e 2015, 30 apresentavam caquexia (grau extremo de emagrecimento) e/ou desnutrição. Ademais, 53 internos faleceram de tuberculose, pneumonias ou complicações decorrentes de infecções pulmonares, sendo que a maior parte dos mortos - 48 pessoas - possuía até 40 anos de idade ${ }^{6}$.

Evidentemente, essa situação não é uma especificidade dos cárceres fluminenses. Em São Paulo, estado que concentra a maior população penitenciária do país mais de 230 mil pessoas reclusas -, a Secretaria de Administração Penitenciária (SAP), apenas em 2014, contabilizou 482 óbitos, sendo que 450 foram categorizados como "mortes naturais". Em 2017, de 532 óbitos computados, 484 foram agrupados na mesma categoria?.

Esses números, vale notar, ressoam em todos os estados da Federação. Entre 2014 e 2017, 6.368 presos e presas morreram nos cárceres brasileiros, sendo que 3.670 casos $(57,6 \%)$ foram tabulados como "mortes naturais". De todos esses óbitos, 472 sequer foram esclarecidos, sendo categorizados pelos distintos estados do país como "causa indeterminada" 8 .

Superlotação em espaços sem ventilação e com pouca luminosidade, racionamento de água potável, acúmulo de lixo, infiltrações, umidade, esgoto e mofo, privação alimentar ou fornecimento de comida estragada, ausência de medicamentos e profissionais de saúde, falta de produtos de higiene e limpeza, infestação de insetos e roedores, alocação da massa carcerária em terrenos contaminados ${ }^{9}$. Trata-se de uma racionalidade governamental que opera a partir de uma "política do definha- 
mento", cuja resultante é a produção de um estado progressivo de decomposição, em que presos e presas vão morrendo paulatinamente - em função das próprias condições de funcionamento dos cárceres (Mallart, 2019).

Ainda que o foco do presente texto esteja nos óbitos por doenças, vale ressaltar que eles são apenas uma peça na maquinaria de produção da morte que é a prisão. Seria possível, por exemplo, abordar os óbitos decorrentes dos conflitos entre facções que, nos primeiros 15 dias de 2017, notadamente em Roraima, Rio Grande do Norte e Amazonas, resultaram em 131 mortos $^{10}$. Ademais, como discutido em outro trabalho, nas periferias de São Paulo a passagem pelo cárcere é mobilizada por grupos de extermínio que, a partir de tatuagens monocromáticas feitas nas prisões, bem como da consulta aos antecedentes criminais das vítimas, decidem quem vive e quem morre, evidenciando que a prisão, ao produzir vidas potencialmente matáveis, retroalimenta outras máquinas de morte (Mallart \& Godoi, 2017). Com efeito - e esse é o ponto a reter -, jamais se deve esquecer que "todo o sistema penal, no fundo, está orientado para a morte e é regido por ela" (Foucault, 2015b: 19).

Da sarna à tuberculose, que atinge a população carcerária diferencialmente - no Rio de Janeiro, as taxas de deteç̧ão de tuberculose nas prisões são 30 vezes maiores do que as observadas na população em liberdade (Sánchez \& Larouzé, 2016) -, passando pelos surtos de sarampo e meningite meningocócica, os cárceres operam como espaços de produção e disseminação de doenças. A lista de enfermidades é vasta, englobando problemas osteomusculares, devido à péssima qualidade dos colchões e à superlotação, enfermidades do aparelho digestivo, relacionadas à dieta oferecida, e doenças respiratórias, decorrentes da aglomeração e ausência de ventilação e iluminação adequadas (Minayo \& Ribeiro, 2016). Isso sem contar a infinidade de sintomas psíquicos provocados ou agravados pelo cotidiano da detenção.

Diante desse estado de coisas, que precede a pandemia, o novo coronavírus surge como mais um fator na composição do massacre, a começar pelo fato de que o racionamento de água e a superlotação em espaços sem ventilação impedem a adoção das medidas mais recomendadas para barrar a contaminação, a saber, lavar as mãos e evitar as aglomerações. Em São Paulo, segundo dados do Núcleo Especializado de Situação Carcerária (Nesc) da Defensoria Pública, produzidos a partir de 130 visitas de inspeção entre abril de 2014 e julho de 2019, 70,8\% das unidades prisionais submetiam os reclusos ao racionamento de água. Ademais, $69 \%$ das prisões estavam superlotadas. Alguns espaços, como o Centro de Progressão Penitenciária (CPP) de Pacaembu, possuíam taxa de $278 \%$ de superlotação, números que exemplificam o que se passa no sistema prisional brasileiro ${ }^{11}$. Dados publicados omissoes-2281 3630>. Acesso em: 05 ago. 2020.

9. É esse o caso do Centro de Detenção Provisória (CDP) da Vila Independência Zona Leste de São Paulo, situado em um terreno que já abrigou diversas indústrias e até mesmo um lixão, solo no qual, segundo o Ministério Público de São Paulo (MP), acumulam-se metano e metais pesados. Para mais informações: <http://g1.globo. com/sao-paulo/ noticia/2012/09/mppede-retirada-depresidio-de-terrenocontaminado-em-sp. html>. Acesso em: 06 ago. 2020

Em relação ao Rio de Janeiro, o complexo de Gericinó, que possui 25 unidades (praticamente a metade do sistema carcerário do estado), tem como vizinho um aterro sanitário.

10. Disponível em: <http://www.r7.com/ retrospectiva-2017/ briga-de-faccoessomou-131mortes-nosprimeiros-15-diasde-2017-25122017>. Acesso em: 13 Ago. 2020.

11. Agradecemos ao Nesc por ter facultado o acesso aos dados citados, em especial, a Thiago de Luna Cury. 
12. Disponível em: <https:// g1.globo.com/rj/ rio-de-janeiro/ noticia/2020/05/20/ rj-tem-48-mortesem-presidiosdurante-quarentenada-covid-19-o-maior numero-em-6-anos. ghtml>. Acesso em: 14 Ago. 2020

13. No início de 2021, tal entrevista foi publicada no Le Monde Diplomatique Brasil (Araújo et alii, 2021). pelo Departamento Penitenciário Nacional mostram que, no primeiro semestre de 2017, enquanto o país atingia a marca de 726.354 presos, havia 423.242 vagas, ou seja, uma taxa de superlotação da ordem de 171,62\% (Infopen, 2017).

Em virtude da atual emergência sanitária, a única medida efetiva a ser adotada em relação às prisões seria uma política massiva de desencarceramento. Ao invés disso, como já discutido por outros pesquisadores (Campello \& Godoi, 2020; Prando et alii, 2020), nota-se a adoção de políticas de negação da crise, assim como ações que reforçam o isolamento e o endurecimento securitário. Acresça-se a isso um processo de produção de desinformação, intensificando o que, há tempos, é um traço marcante do sistema penitenciário - a ilegibilidade.

Não obstante, apesar de todos os esforços de ocultação - o segredo é uma das armas do exercício do poder político (Foucault, 2015a) -, o crescimento dos óbitos é evidente. No Rio de Janeiro, entre 11 de março, data do primeiro decreto de isolamento social, e 15 de maio de 2020, 48 presos faleceram, aumento de 33\% em relação ao mesmo período de $2019^{12}$. Como observam os integrantes do Mecanismo Estadual de Prevenção e Combate à Tortura, tendo por base uma série de dados coletados, entre os quais a disparada no número de óbitos em determinadas unidades prisionais, é possível dizer que o novo coronavírus e as doenças respiratórias contribuíram para a aceleração das mortes. Contudo, vale realçar que o aumento no volume de mortos não se deve apenas a tal enfermidade.

Mesmo tendo muitas mortes por Síndrome Respiratória Aguda Grave (SRAG), o maior volume de mortes são de outros agravos que correm paralelamente no sistema e que não foram tratados durante a pandemia. Então, por exemplo, você tem pessoas que convivem com HIV com infecção por tuberculose, tem casos de tuberculose e toxoplasmose, muita gente com emagrecimento ou caquexia. Interromperam tudo com o medo da Covid-19 e acabou que as pessoas começaram a morrer em muito volume por causas secundárias que já estavam presentes antes (integrante do Mecanismo Estadual de Prevenção e Combate à Tortura/RJ; entrevista realizada em 20 Nov. 2020) $)^{13}$.

Sem desconsiderar os impactos imediatos da Covid-19, observa-se que o aumento no número de mortos não se restringe às complicações desencadeadas pela doença em si. Em nome do suposto enfrentamento à pandemia, suspendeu-se a realização das visitas familiares e, por conseguinte, reduziu-se a entrada de mantimentos que atenuam a pouca quantidade e a péssima qualidade da alimentação fornecida pelos órgãos penitenciários - daí a hipótese dos integrantes do MEPCT/RJ de que o número elevado de pessoas desnutridas quando de suas últimas visitas, entre ou- 
tros fatores, esteja ligado a tal interrupção ${ }^{14}$. Simultaneamente, reativaram-se propostas que já foram denunciadas à Organização das Nações Unidas (ONU). Se, em 2010, presos do Espírito Santo foram flagrados em situação degradante no interior de contêineres, em meados de 2020, o Departamento Penitenciário Nacional (Depen) aventou a possibilidade de confinar as pessoas idosas e do grupo de risco em tais estruturas metálicas. Por mais que a proposta tenha sido barrada, ela mostra qual é o horizonte das medidas imaginadas pelos órgãos competentes. Ao mesmo tempo, interromperam-se os atendimentos médicos - desde sempre deficitários e a distribuição de medicamentos para o tratamento de doenças como tuberculose e HIV/Aids, cujos efeitos são devastadores no que concerne à manutenção da vida dos pacientes. Em relação aos casos suspeitos de contaminação pelo novo coronavírus, estes foram retirados do convívio com a massa carcerária, sendo isolados em celas para o cumprimento de sanção disciplinar, isto é, o que era para ser um isolamento com caráter profilático converteu-se em confinamento nas celas de castigo. Todas, e cada uma dessas ações, evidenciam que a gestão penitenciária da crise sanitária, ao contrário de conter a propagação do vírus, alarga o espaço da morte.

Nessa direção, no que se refere ao número de mortos, como bem salientam os integrantes do mecanismo, na verdade, os poucos dados disponíveis sugerem um quadro de subnotificação, haja vista que, entre outros fatores, os presos e as presas que conseguem acessar a rede externa de saúde e, porventura, vêm a óbito, podem não ser computados como mortos da Secretaria de Estado de Administração Penitenciária (Seap) ${ }^{15}$. Soma-se a esse processo de registrar a morte fora das muralhas - não é incomum ouvir de presos e de presas que há casos de sujeitos que, quando transferidos, já estavam mortos -, o fato de que as próprias categorias de classificação dos óbitos ("mortes naturais" e "causa indeterminada"), longe de explicarem algo, mascaram o processo de fabricação da matança. Esses registros acabam por encobrir a tortura sistemática, a violação de direitos básicos, as precariedades estruturais e a política do "fazer definhar"; daí a necessidade de desvelar toda a maquinaria estatal por trás dessas categorias de ocultação.

Com efeito, não é em vão que nos primeiros meses de pandemia, e a despeito dos parcos números disponíveis, já se notava que a mortalidade por Covid-19 no interior dos cárceres brasileiros era cinco vezes maior do que a taxa observada fora dos muros $^{16}$. Porém, o que não se imaginava é que mais letal do que o vírus em si-que encontra nas condições das prisões o cenário ideal para a sua propagação - são as medidas adotadas pelas autoridades competentes. É exatamente na produção e na manutenção de condições estruturais precárias - que submetem presos e presas a uma vida impossível de ser vivida - que a morte se dilata.
14. Em nota divulgada recentemente, a Plataforma Desencarcera/RJ anotou o aumento de denúncias entre 25 de novembro e 2 de dezembro de 2020. Em tal período, houve 98 reclamações referentes à ausência ou quantidade insuficiente de alimentos, à falta de acesso à água ou fornecimento de água imprópria para o consumo, além de casos de corte de energia elétrica. O documento traz ainda dados produzidos pelo MEPCT/RJ, referentes a presos que vieram a óbito durante a pandemia. De 141 corpos, 20 deles estavam desidratados, desnutridos, emagrecidos e com caquexia (disponível em: <https:// www.facebook. com/frentepelo desencarceramento/ posts/123477 1173590377? tn__=K-R>). No que tange à volta das visitas, estas foram retomadas na semana de 10 de setembro, todavia, com uma série de restrições, entre as quais a não realização de visitas íntimas e a redução na frequência da visitação.

15. Disponível em: $<$ https://drive. google.com/drive/ folders/1JDbdNU 870wFLJR7na_ 
wFE1vSMkIG 3JaV>. Acesso em: 20 Ago. 2020. Sobre isso, vale acessar o "Relatório parcial sobre os impactos do Covid-19 no sistema prisional do Rio de Janeiro. Informações adicionais até o dia 09 de agosto de $2020^{\prime \prime}$.

16. Disponível em: $<$ https://www1. folha.uol.com.br/ cotidiano/2020/05/ letalidade-docoronavirus-entrepresos-brasileirose-o-quintuploda-registrada-napopulacao-geral. shtml>. Acesso em: 22 Ago. 2020

\section{Este trecho} faz parte de uma entrevista realizada com um grupo de médicos que atua na clínica da família Maria do Socorro, localizada na Rocinha. Intitulada

"Contextualizar o desmonte é essencial", a entrevista aborda os impactos da pandemia no território, o desmonte do "Programa Saúde da Família", entre outros assuntos. Disponível em: <https:// diplomatique.org br/contextualizaro-desmonte-eessencial/>. Acesso em: 01 Out. 2020. Por sua vez, o trecho subsequente resulta de uma entrevista posterior realizada somente com Letícia Renck Bimbi, médica que compõe a

\section{O edifício subterrâneo na favela vertical: ar, luz e umidade}

Na área geográfica da minha população, nós temos um prédio de 13 andares em que o nível da rua fica, mais ou menos, no décimo andar do prédio. Então, para você entrar, você desce um beco 10 andares de beco - e a porta é lá embaixo. E aí você sobe 13 andares de escada. As pessoas que vivem no primeiro, segundo, terceiro e quarto andares, elas basicamente vivem em um subsolo úmido, com mofo, e é um beco com, sei lá, menos de um metro de largura. São coisas que já explicam muitas das doenças infecciosas, como a tuberculose. Além disso, há a aglomeração de pessoas, já que a densidade demográfica é muito grande. Vivem muitas pessoas em um cômodo ${ }^{17}$.

[...] tem o fator da Rocinha ser uma favela muito vertical, então, isso predispõe a lugar abafado, sem sol, sem iluminação, sem ventilação, né? Estão, cada vez mais, estourando prédios maiores. [...] tem essa característica: mesmo sendo um lugar mais arrumado, digamos, eles continuam sendo em becos escuros, vários andares, grudado na janela do vizinho, pouca iluminação, então, é muito difícil, a grande maioria das casas que eu entro não tem janela que bate sol. [...] quem tem janela que bate sol é bem privilegiado e esses lugares são mais caros de alugar, então, tem a questão de a favela ser vertical, que predispõe a ter becos muito estreitos e muito pouca iluminação. [...] tem a questão também de a Rocinha ser feita num lugar que é uma floresta, né? O Morro do Dois Irmãos era uma floresta que foi desmatada, é super úmido. A condição perfeita para disseminar um problema respiratório é essa. Lugar abafado, úmido e grande concentração de pessoas, densidade demográfica altíssima e prédios altos onde antes era uma floresta. O maior determinante social da Rocinha ser um dos maiores polos de tuberculose do Brasil é a condição de moradia. Além das doenças infecciosas, pela questão da aglomeração mesmo, da falta de ventilação, tem muita alergia respiratória - asma, rinite -, quem tem predisposição a ser alérgico piora muito nesses lugares. Bom, e aí, outras doenças: acho que principalmente a questão do esgoto. Se você perguntar pra maioria dos moradores e agentes de saúde o que mais precisa na Rocinha, eles vão falar da rua do valão. Que é uma rua onde tem uma vala de esgoto a céu aberto, que é onde junta várias valas que vem de toda a Rocinha. [...] quando chove, aquilo ali extravasa. Então, fica um grande mar de esgoto. E ali, bom, verminose, um monte de doença... ali é o local de criação da doença, aquilo não existiria se não tivesse esse valão, é só fazer o esgoto fechado que ninguém vai ter verminose, diarreia infecciosa, essas coisas. 
Canais de esgoto a céu aberto, os quais desembocam em um valão; nos dias de chuva abundante, este se transforma em um "mar de esgoto". Becos e vielas estreitos e escuros. Um edifício em que os primeiros andares remetem a um subsolo úmido, com mofo pelas paredes. Prédios que, em virtude da proximidade das construções, impossibilitam a penetração dos raios solares e reduzem a ventilação. Densidade demográfica. Moradias situadas em um morro, cuja umidade faz recordar a floresta devastada; muitas das casas, cravadas nas encostas, encontram-se em áreas com risco de desabamento. É em virtude dessas distintas precariedades estruturais - às quais poder-se-iam acrescentar o acúmulo de lixo, as interrupções no fornecimento de água potável, os restos de obras e entulhos etc. - que as condições de produção e de transmissão de determinadas doenças são potencializadas.

A lista de enfermidades é extensa. Àquelas diretamente relacionadas às precariedades estruturais, somam-se as dores osteomusculares - as quais decorrem da natureza extenuante do trabalho desenvolvido, assim como das longas jornadas -, as doenças do aparelho digestivo, vinculadas à dieta consumida, além das já conhecidas diabetes, hipertensão e obesidade, cuja prevalência em estudos populacionais - como sublinha Letícia, médica de saúde da família da Rocinha - "é sempre maior em lugares com piores condições de vida"18.

Do prisma das condições estruturais precárias, compreende-se alguns dos motivos pelos quais a Rocinha, a maior área de favela da cidade do Rio de Janeiro, é um dos principais focos de tuberculose do país, sendo que a incidência da doença no território é dez vezes maior do que a média nacional, 5,5 vezes maior que a média do estado e 4,5 vezes maior que a do município (Gondim, 2016). Todavia, como bem demonstra Roberta Gondim, não é só em tal localidade que a taxa de incidência da doença é mais elevada. Na medida em que as áreas mais densamente povoadas pelas populações de baixa renda são as mais afetadas pela doença, constata-se que "o comportamento da tuberculose espelha a cartografia da desigualdade na cidade do Rio de Janeiro" (Gondim, 2016: 119) ${ }^{19}$. Ademais, essa distribuição diferencial, que separa estados e municípios, rebate na própria circunscrição dos territórios afetados. Na Rocinha, as regiões mais pobres e insalubres são as que abrigam a maior quantidade de residentes com tuberculose, demonstrando a existência de um gradiente interno de precariedades.

Se, nas prisões fluminenses, as taxas de detecção de tuberculose são 30 vezes maiores do que as observadas fora dos muros (Sánchez \& Larouzé, 2016), nas favelas e periferias - que são os territórios urbanos onde se captura o grosso da massa carcerária -, o risco de contrair tal enfermidade, se comparado com outras áreas equipe supracitada, e a quem agradecemos imensamente pelas parcerias e trocas.

18. Estudos recentes indicam que a segregação econômica e social está relacionada à maior prevalência de hipertensão e diabetes, independentemente de características individuais como idade, histórico familiar etc. Disponível em: <https://agencia. fiocruz.br/estudoassocia-segregacaohipertensao-ediabetes>. Acesso em: 12 Dez. 2020

19. Pereira et alii (2015) também alertaram para as conexões entre as zonas de pobreza e a tuberculose. Tal como a Rocinha, os bairros de Bonsucesso, Jacaré e Santo Cristo são alguns com a maior incidência da doença. 
da cidade, é superior. Do ângulo aqui adotado, observa-se que as mesmas condições que fomentam a transmissão da doença no interior dos cárceres ecoam na densidade demográfica, nos becos escuros e apertados, nas moradias sem janelas, pouco iluminadas e com inúmeras pessoas partilhando o mesmo cômodo. Esses traços, entre outros, fazem com que a tuberculose componha o quadro das doenças próprias das desigualdades - denominadas negligenciadas (Morel, 2004) -, isto é, enfermidades que são mais frequentes em espaços que concentram a pobreza.

Com efeito, estudos que articulam território, precariedades estruturais, enfermidades e mortes vêm de longa data. Em Sobre a maneira de transmissão do cólera, John Snow (1999) já mostrara que as epidemias que assolaram a cidade de Londres, em meados do século XIX, tinham como principal fator de propagação o esgoto misturado à água potável. Ao questionar a teoria dos miasmas - por meio da qual se acreditava que a causa do cólera residia no odor fétido exalado dos populosos bairros de trabalhadores -, a pesquisa do médico, que inaugura a epidemiologia moderna, coloca no centro de suas reflexões os problemas relacionados ao abastecimento de água. Ainda que tal doença se propagasse por grandes extensões, atingindo até mesmo as classes mais altas da comunidade, Snow demonstrara que, mesmo nos distritos abastecidos com a mesma água, os efeitos do cólera eram mais letais nos que concentravam a pobreza, territórios onde a população vivia em "estado de aglomeração" (Snow, 1999: 85). Além disso, o autor anotara os efeitos devastadores em instituições para crianças e alienados, inseparáveis das condições precárias em que tais pessoas eram confinadas.

Em outro registro, Mike Davis (2006), ao analisar o potencial de devastação da gripe aviária - entrincheirada em nichos ecológicos produzidos pelo agrocapitalismo global -, demonstra como a nossa vulnerabilidade a essa e a outras doenças emergentes, entre diversos fatores, é inseparável da pobreza urbana concentrada, assim como da crescente deterioração de infraestruturas de saúde pública. Ao retomar a discussão sobre a gripe de 1918 - chamada de gripe espanhola -, Davis se debruça sobre as taxas de letalidade na Índia, revelando como os pobres foram vítimas de uma sinergia perversa entre desnutrição e pneumonia bacteriana. Ao sublinhar a correlação entre classe e mortalidade em todos os países, o autor afirma que aqueles que escreveram sobre o que ocorreu em 1918 observaram a afinidade da pandemia "pela pobreza, por condições habitacionais abaixo dos padrões e por dietas inadequadas" (Davis, 2006: 40). Se a densidade populacional, as condições sanitárias e de moradia são centrais na disseminação de doenças transmitidas pelo ar, zonas de pobreza são locais ideais. "Segundo este critério, a gripe pandêmica e outras infecções letais têm um futuro brilhante" (Davis, 2006: 189). 
Diante dessas ponderações, não espanta que a leitura visionária do autor já tenha se concretizado. Se, inicialmente, a Covid-19 atingiu as camadas abastadas da população, sendo os primeiros casos resultantes de viagens ao exterior, nos meses posteriores era evidente que a propagação do vírus e a letalidade passavam a afetar os estratos mais pobres. Em São Paulo, bairros periféricos chegaram a ter dez vezes mais óbitos do que os distritos mais ricos. Na Cidade Tiradentes, extremo da Zona Leste, do início da pandemia até 2 de julho de 2020, de acordo com números da Secretaria Municipal de Saúde, foram registradas 223 mortes; no mesmo período, a Barra Funda, bairro situado na Zona Oeste da cidade, contabilizou 21 óbitos ${ }^{20}$.

No que concerne ao Rio de Janeiro, um estudo elaborado pelo Instituto de Pesquisa Econômica Aplicada (Ipea) mostrou que, apesar da doença, em um primeiro momento, ter se espalhado pelos bairros da Zona Sul, foram nas regiões periféricas que a Covid se tornou mais mortífera. Tendo em conta o período do levantamento (8 de março a 13 de junho de 2020), observa-se que a letalidade nos bairros com menor Índice de Desenvolvimento Social (IDS 1 e 2) foi o dobro em relação às localidades de IDS 5. Se comparados os extremos, o cenário é mais alarmante. Ao passo que na Lagoa (maior IDS da capital) foram registrados 284 casos e 20 mortes, em Paciência, bairro da zona oeste com IDS 1, houve 435 casos e 110 óbitos ${ }^{21}$. Essa situação, em que negros e pobres são as vítimas principais do vírus - nunca é demais lembrar, também o são da seletividade do aparato penal -, rebate não só em todo o território nacional, mas em países como Estados Unidos e Reino Unido. Nos Estados Unidos, dados do APM Research Lab evidenciam que, enquanto os negros morreram a uma taxa de 50,3 por 100 mil habitantes, para os brancos esse número ficou em 20,7 - mais do que o dobro 22 .

No âmbito da questão que nos interessa investigar, as ressonâncias entre prisões, favelas e periferias são inequívocas. As mesmas precariedades estruturais que favorecem a disseminação de doenças como a tuberculose fomentam o contágio pelo novo coronavírus. Em ambos os lados dos muros, a possibilidade de seguir os protocolos de isolamento e os cuidados básicos recomendados pelas autoridades sanitárias inexiste, revelando o descompasso entre as orientações ditas universais e o que se passa na realidade desses lugares. Ao passo que para os presos, os quais subsistem em locais superlotados, a recomendação de isolamento soa como uma retórica sem fundamento ou, então, como sinônimo de tranca no castigo, nas favelas e periferias, seja em virtude da falta de espaços físicos, seja pelo fato de que é imperioso seguir com os afazeres cotidianos para garantir as mínimas condições de existência, permanecer em casa não é uma possibilidade. Soma-se a isso, a água que nem sempre escorre pela torneira ${ }^{23}$, as construções que inviabilizam a penetra-
20. https://noticias. uol.com.br/ultimasnoticias/agenciaestado/2020/07/11/ pobres-de-sp-temmais-risco-de-mortepor-covid-19.htm. Acesso em: $14 \mathrm{dez}$. 2020.

21. https://www. brasildefato.com. br/2020/08/05/ maioria-das-mortespor-covid-no-rio-ede-moradores-dosbairros-mais-pobresdiz-ipea. Acesso em: 14 dez. 2020.

22. Disponível em: $<$ https://www.bbc. com/portuguese/ brasil-53338421> Acesso em: 15 Dez. 2020.

23. Vale destacar que o racionamento de água, que há tempo afeta as prisões, ecoa em diversas periferias do país. $\mathrm{O}$ abastecimento de água, também caracterizado por desigualdades espaciais e sociais, mostra como populações e territórios periféricos são especialmente prejudicados. Para uma análise sobre o fornecimento de água nas favelas da periferia da cidade do Rio de Janeiro, ver Gustavo Prieto (2011). 
24. Não são só as prisões que são construídas em terrenos instáveis e contaminados.

Apenas para citar um exemplo, em 7 de abril de 2010, um deslizamento de terra matou 48 moradores no Morro do Bumba, localizado em Niterói. O terreno, com centenas de casas, no passado, abrigava um lixão (disponível em: <http://g1.globo. com/rio-de-janeiro/ noticia/2015/04/ tragedia-do-bumbacompleta-5-anos-eainda-ha-familiasem-risco-no-rj.html> Acesso em: 15 Dez. 2020). ção dos raios solares e restringem a circulação do ar, a alocação dessas populações em solos contaminados ${ }^{24}$, o esgoto, o acúmulo de lixo, a fome.

Em tal contexto, prisão-favela-periferia constituem um continuum de espaços físicos e sociais, que ressoam em termos de precariedades estruturais e materialidades. Lugares em que circulam e habitam determinadas populações, inscrevendo os mesmos marcadores sociais de classe e raça/cor tanto nas periferias como nos cárceres. Espaços nos quais, como na cidade do colonizado, "morre-se em qualquer parte, de qualquer coisa" (Fanon, 2015: 43).

A pandemia do novo coronavírus, ao escancarar desigualdades preexistentes, clarifica, de forma ainda mais atroz, a exposição diferencial de determinadas populações e territórios à pobreza, às doenças, à fome, às múltiplas formas de violência do Estado (Butler, 2018). Vidas que, nos tempos que correm, estão mais expostas aos danos da Covid-19, bem como aos efeitos das crises sanitária, política, econômica e social que dela decorrem.

\section{Considerações finais: infraestruturas e políticas de morte}

A prisão é parte de um conjunto de dispositivos governamentais dedicados seletivamente à gestão de populações residentes em favelas e periferias. Essa gestão articula uma miríade de atores, políticas e instituições, com destaque para as íntimas relações entre polícias, sistema de justiça e cárceres, os quais constituem o coração das políticas de segurança pública. Sob a égide das obsessões securitárias e da lógica militarizada de governo dessas populações e territórios, consideradas como indesejáveis (Telles, 2019), tais políticas e instituições alimentam as imaginações e os estereótipos que recaem sobre favelas, periferias e seus moradores, vistos como ameaça à lei e à ordem, ameaça ambiental, ameaça à cidade. É justamente nesse contexto que os mortos pela polícia são sistematicamente enquadrados em categorias como "traficante", figura paradoxal do apagamento e da hipervisibilidade (Vianna, 2019). Sem nome, rosto ou história, seguem como eternos "suspeitos", convertidos em "incivilizados" e "perigosos".

Naquilo que concerne ao aparato carcerário, vale destacar que ele corresponde a um dos mecanismos por meio dos quais o poder do Estado opera a marcação de corpos jovens, negros, favelados/periféricos e pouco escolarizados. Assinatura do Estado sobre corpos, populações e territórios, que ocorre a partir da conexão com outras instâncias institucionais, procedimentos administrativo-documentais e políticas destinadas à vigilância, controle e repressão. Marcação que também ope- 
ra pela exposição das pessoas presas à vulnerabilidade corporal característica da própria condição carcerária, decorrente da relação do corpo com uma série de materialidades infraestruturais regidas por condições de precariedade, cuja imagem exemplar são os corpos desnutridos, desidratados, caquéticos.

Por outro lado, como descrevemos e argumentamos ao longo do texto, do lado de fora dos muros, há populações que se encontram em e são marcadas por condições de existência que também dizimam a viabilidade da vida - condições, aliás, agravadas pela crise sanitária gerada pela pandemia de Covid-19.

O ponto a sublinhar é a existência de um campo de continuidades entre prisões, favelas e periferias, a partir das relações entre precariedade das infraestruturas, vulnerabilidade corporal e políticas de morte, no nosso caso, com enfoque nos óbitos por doenças.

Se, como destaca Judith Butler (2018: 147), um corpo "é definido pelas relações que fazem a sua vida e a sua ação possível", não se pode compreender a vulnerabilidade corporal "fora dessa concepção de suas relações constitutivas com outros humanos, processos vivos, condições inorgânicas e meios de vida" (Butler, 2018: 147). Nessa chave, as infraestruturas são parte fundamental dos suportes que tornam a vida possível de ser vivida, suportes não humanos da vida corporal. Na medida em que somos dependentes de outros corpos, de redes de apoio e de infraestruturas "o homem não fica de pé sozinho" (Butler, 2018: 145) -, é importante notar como as políticas contemporâneas de produção da morte operam nesse mesmo registro.

Em Cidades sitiadas: o novo urbanismo militar, Stephen Graham (2016), ao discorrer sobre as novas modalidades de guerra, mostra como as cidades modernas, com as suas complexas redes de infraestruturas, não são apenas o lócus do combate, mas instrumento ativo da própria guerra - uma guerra infraestrutural. Nesse cenário, o ataque às infraestruturas urbanas - por exemplo, sistemas de água, saneamento e redes de eletricidade e comunicação - tem como principal efeito a letalidade em massa, provocada, inclusive, pela disseminação de doenças.

Em 1991, as táticas militares norte-americanas de destruir o sistema elétrico iraquiano, ao impedirem o funcionamento das usinas de tratamento de água e de esgoto, resultaram "em epidemias de gastroenterite, cólera e tifo, levando a até 100 mil mortes de civis" (Graham, 2016: 362). Do mesmo modo, as forças militares israelenses, em seus cercos ininterruptos à Cisjordânia e à Faixa de Gaza, centram seus esforços na demolição de casas, no desmantelamento de estradas, no fuzilamento de reservatórios de água, na destruição de sistemas de tratamento de es- 
goto. Em Gaza, durante a chamada operação "Chuva de Verão", realizada em 2006, após o bombardeio de uma estação elétrica, os efeitos gerados na saúde pública foram brutais, entre eles, o aumento exponencial dos casos de diarreia aquosa e sanguinolenta, de desnutrição infantil e de mortes de pacientes dependentes de diálise, impedidos de realizar as sessões de tratamento na frequência adequada (Graham, 2016: 377-378). Nitidamente, vê-se que na operação do necropoder, o qual desdobra o mundo em "mundos da morte" (Mbembe, 2018: 71), a destruição das infraestruturas é fulcral.

Nesse ponto, sem desconsiderar que a militarização da gestão urbana, tal como proposta por Stephen Graham, ressoa no cenário brasileiro, parece-nos importante estabelecer algumas distinções, afinal há diferentes matizes entre as políticas que buscam explicitamente a morte de determinadas populações e aquelas que produzem ou mantém condições de degradação que fazem com que as pessoas morram. No âmbito deste artigo, não se trata de enfatizar a destruição de infraestruturas, mas de realçar os efeitos da inexistência, da manutenção e da construção de determinadas infraestruturas, que ao invés de expandirem as condições de vida, adoecem, fazem definhar. É por essa razão que a reivindicação não é pela construção de qualquer infraestrutura, afinal, algumas delas - por exemplo, as prisões - servem à aniquilação da vida.

Com efeito, certas infraestruturas e condições de precariedade possuem a potencialidade de produzir processos de definhamento corporal e de rebaixamento moral que, como anotou Taniele Rui (2012), em sua etnografia sobre cenários de uso e venda de crack, dão forma a uma corporalidade em que ganha destaque a abjeção. Corpos produzem espaços, materialidades e infraestruturas, mas o movimento inverso também ocorre, de modo que nessa relação o estigma de um alimenta o outro. É o estigma sobre a favela e o favelado, o periférico e o negro, considerados como indesejáveis, que sustenta e justifica a distribuição desigual de doenças e mortes, as quais poderiam ser evitadas, mas não o são - seja nas prisões ou mesmo fora delas. Vidas construídas como inimigas e abjetas, empurradas para uma zona de arbítrio, cuja gestão opera a partir de mecanismos igualmente abjetos, como as instituições carcerárias.

A título de conclusão, vale retomar duas propostas de intervenções estruturais voltadas às favelas e prisões, ambas desenvolvidas com o objetivo de conter a propagação da tuberculose nesses espaços. No primeiro caso, no plano do Programa de Aceleração do Crescimento (PAC), destaca-se um conjunto de obras de urbanização feitas na favela da Rocinha, no início da década de 2010. Atemo-nos, especialmen- 
te, ao alargamento da chamada Rua 4 que, após as reformas, as quais permitiram a entrada dos raios solares e a circulação do ar em novas residências, deixou de ser conhecida como o "beco da tuberculose", cujo número de casos, que durante muito tempo foram os mais elevados da favela, chegou a zero ${ }^{25}$. Na outra ponta, sublinhamos a produção de um "Manual de intervenções ambientais para o controle da tuberculose nas prisões" (DPN, 2012), realizado pelo Departamento Penitenciário Nacional em parceria com outras instituições. Nele, visto que a ausência de ventilação e de luz solar adequadas são fatores cruciais na disseminação da doença, são apresentadas propostas para a melhoria das condições ambientais dos cárceres, com destaque para a abertura de janelas, entre outras intervenções que fomentem a ventilação e a iluminação natural de tais ambientes, estejam eles construídos ou por construir.

Sem desprezar que o combate às doenças respiratórias não deve se resumir às medidas biomédicas, e que a abertura de ruas e janelas impactam diretamente nas condições ambientais de favelas e prisões, consequentemente, na saúde dessas populações, gostaríamos de sugerir outro ângulo para refletir sobre essas ações. Quando a abertura de uma rua em uma das maiores favelas do país e de uma janela em uma das muitas celas hiperlotadas do sistema penitenciário gera efeitos tão significativos para as vidas que subsistem nesses lugares, é porque a questão se situa muito além de tais medidas. Embora elas possam ser eficazes em termos sanitários, é a existência dessas condições de existência que devem ser sistematicamente questionadas, ainda mais em tempos de Covid-19. Abrir uma janela na cela e uma rua na favela, em realidade, só clarifica o quão ignominioso é o processo de gestão dessas populações e territórios urbanos.

\section{Referências}

ARAÚJO, Fábio. A prisão e a produção do espaço urbano: territorialidades carcerárias. In: MALLART, F.; GODOI, R. (Orgs.). BR 111: a rota das prisões brasileiras. São Paulo: Veneta, 2017.

ARAÚJO, Fábio; MALLART, Fábio; CANDOTTI, Fábio; GODOI, Rafael. A produção da calamidade: um balanço das prisões fluminenses em 2020. Le Monde Diplomatique Brasil, São Paulo, 11 Jan. 2021. Disponível em: <https://diplomatique.org.br/a-producao-da-calamidade-um-balanco-das-prisoes-fluminenses-em-2020/>. Acesso em: 13 Jan. 2021.
25. Disponível em: <https:// brasil.elpais.com/ brasil/2015/09/01/ politica/14411 20198_053979. html>. Acesso em: 29 Dez. 2020 
BARBOSA, Antônio Rafael. Prender e dar fuga: biopolítica, tráfico de drogas e sistema penitenciário no Rio de Janeiro. Tese (Doutorado em Antropologia Social) Departamento de Antropologia, Universidade Federal do Rio de Janeiro, Rio de Janeiro, 2005.

BONY, Lucie. La prison, une cité avec des barreaux? Continuum socio-spatial par-delà les murs. Annales de géographie, n. 702-703, p. 275-299, 2015.

BUMACHAR, Bruna Louzada. Nem dentro, nem fora: a experiência prisional de estrangeiras em São Paulo. Tese (Doutorado em Antropologia Social) - Departamento de Antropologia, Universidade Estadual de Campinas, Campinas, 2016.

BUTLER. Judith. Corpos em aliança e a política das ruas: notas para uma teoria performativa de assembleia. Rio de Janeiro: Civilização Brasileira, 2018.

CAMPELLO, Ricardo; GODOI, Rafael. Tranca, contêiner e bomba: a gestão penitenciária da pandemia no Brasil. Le Monde Diplomatique Brasil, São Paulo, 3 Jul. 2020. Disponível em: <https://diplomatique.org.br/tranca-conteiner-e-bomba-a-gestao-penitenciaria-da-pandemia-no-brasil/>. Acesso em: 24 Dez. 2020.

CLEMMER, Donald. The prison community. New York: Holt, Rinehart and Winston, 1958.

The prison community. New York, Rinehart \& Co., 1940.

COMBESSIE, Philippe. La ville et la prison une troublante cohabitation. Revue Projet, n. 269, p. 70-76, 2002.

COMFORT, Megan. Partilhamos tudo o que podemos: a dualização do corpo recluso nos romances através das grades. Análise Social, v. 62, n. 185, p. 1055-1079, 2007.

CUNHA, Manuela I. Da relação prisão-sociedade. Atualização de um balanço. In: CUNHA, M. I. (Org.). Do crime e do castigo: temas e debates contemporâneos. Lisboa: Editora Mundos Sociais, 2015.

As organizações enquanto unidades de observação e de análise: o caso da prisão. Etnográfica, v. 8, n. 1, p. 151-157, 2004.

Entre o bairro e a prisão: tráfico e trajectos. Lisboa: Fim de Século, 2002.

DAVIS, Mike. O monstro bate à nossa porta. Rio de Janeiro: Record, 2006.

DEPARTAMENTO PENITENCIÁRIO NACIONAL (DPN). Manual de intervenções ambientais para o controle da tuberculose nas prisões. Rio de Janeiro: DPN, 2012. 
FANON, Franz. Os condenados da terra. Lisboa: Letra Livre, 2015.

FOUCAULT, Michel. Ditos e escritos, v. IV: "Estratégia, poder-saber". Rio de Janeiro: Forense Universitária, $2015 \mathrm{a}$.

. A sociedade punitiva: curso no Collège de France (1972-1973). São Paulo: WMF Martins Fontes, 2015b.

Vigiar e punir. Petrópolis, RJ: Vozes, 1987.

GARLAND, David (Org.). Mass imprisonment: social causes and consequences. London: Sage, 2001.

GODOI, Rafael. Fluxos em cadeia: as prisões em São Paulo na virada dos tempos. São Paulo: Boitempo, 2017.

GOFFMAN, Erving. Manicômios, prisões e conventos. São Paulo: Perspectiva, 1974.

GONDIM, Roberta. Doenças, corpos e territórios negligenciados: práticas de saúde sobre tuberculose em espaços e pessoas vulnerabilizadas. Tese (Doutorado em Governação, Conhecimento e Inovação) - Faculdade de Economia, Universidade de Coimbra, Coimbra, PT, 2016.

GRAHAM, Stephen. Cidades sitiadas: o novo urbanismo militar. São Paulo: Boitempo, 2016.

GRUPO DE PESQUISA CIDADE E TRABALHO. (Micro)políticas da vida em tempos de urgência. Seção Especial Reflexões na Pandemia - Revista Dilemas, Rio de Janeiro, 24 Ago. 2020. Disponível em: <https://www.reflexpandemia.org/texto-59>. Acesso em: 24 Dez. 2020.

INFOPEN. Levantamento Nacional de Informações Penitenciárias. Brasília: Ministério da Justiça e Segurança Pública. Departamento Penitenciário Nacional, 2017.

MALLART, Fábio. Findas linhas: circulações e confinamentos pelos subterrâneos de São Paulo. Tese (Doutorado em Sociologia) - Departamento de Sociologia, Universidade de São Paulo, São Paulo, 2019.

Salve geral: áreas urbanas, instituições prisionais e unidades de internação da Fundação CASA em comunicação. R@u, v. 3, n. 1, p. 293-314, 2011.

MALLART, Fábio; GODOI, Rafael. Vidas matáveis. In: MALLART, F.; GODOI, R. (Orgs.). BR 111: a rota das prisões brasileiras. São Paulo: Veneta, 2017.

MALLART, Fábio; RUI, Taniele. Por uma etnografia das transversalidades urbanas: 
entre o mundão e os dispositivos de controle. In: MELO, J.; SIMIÃO, D.; BAINES, S. Ensaios sobre justiça, reconhecimento e criminalidade. Natal: Editora UFRN, 2016.

MBEMBE, Achille. Necropolítica. São Paulo: n-1 edições, 2018.

MINAYO, Maria Cecília de Souza; RIBEIRO, Adalgisa Peixoto. Condições de saúde dos presos do estado do Rio de Janeiro. Ciência \& Saúde Coletiva, v. 21, n. 7, p. 2031-2040, 2016.

MOREL, Carlos M. A pesquisa em saúde e os objetivos do milênio: desafios e oportunidades globais, soluções e políticas nacionais. Ciência \& Saúde Coletiva, v. 9, n. 2, p. 261-270, 2004.

MORELLE, M. La prison, la police et le quartier. Gouvernement urbain et illégalismes populaires à Yaoundé. Annales de Géographie, n. 702-703, p. 300-322, 2015.

PADOVANI, Natália. Sobre casos e casamentos: afetos e amores através de penitenciárias femininas em São Paulo e Barcelona. Tese (Doutorado em Antropologia Social) - Departamento de Antropologia, Universidade Estadual de Campinas, Campinas, SP, 2015.

PEREIRA, Alessandra Gonçalves Lisbôa; MEDRONHO, Roberto de Andrade; ESCOTEGUY, Cláudia Caminha; VALENCIA, Luis Iván Ortiz; MAGALHÃES, Mônica de Avelar Figueiredo Mafra. Distribuição espacial e contexto socioeconômico da tuberculose. Rev Saúde Pública, n. 49, 2015.

PIEROBON, Camila. Tempos que duram, lutas que não acabam: o cotidiano de Leonor e sua ética de combate. Tese (Doutorado em Ciências Sociais) - Programa de Pós-Graduação em Ciências Sociais, Universidade do Estado do Rio de Janeiro, Rio de Janeiro, 2018.

PRANDO, Camila; FREITAS, Felipe; BUDÓ, Marília de Nardim; CAPPI, Ricardo. A pandemia do confinamento: políticas de morte nas prisões. Le Monde Diplomatique Brasil, São Paulo, 3 Jun. 2020. Disponível em: <https://diplomatique.org.br/a-pandemia-do-confinamento-politicas-de-morte-nas-prisoes/>. Acesso em: $24 \mathrm{dez}$. 2020.

PRIETO, Gustavo Francisco Teixeira. A sede do capital: o abastecimento de água em favelas da periferia da cidade do Rio de Janeiro. Dissertação (Mestrado em Geografia) - Departamento de Geografia, Universidade de São Paulo, São Paulo, 2011.

RUI, Taniele. Nas tramas do crack: etnografia da abjeção. São Paulo: Terceiro Nome, 2014. 
RUSCHE, Georg; KIRCHHEIMER, Otto. Punição e estrutura social. Rio de Janeiro: Revan, 2004.

SÁNCHEZ, Alexandra; LAROUZÉ, Bernard. Controle da tuberculose nas prisões, da pesquisa à ação: a experiência do Rio de Janeiro, Brasil. Ciência \& Saúde Coletiva, v. 21, n. 7, p. 2071-2079, 2016.

SNOW, John. Sobre a maneira de transmissão do cólera. São Paulo; Rio de Janeiro: Hucitec; Abrasco, 1999.

SYKES, Gresham; MESSINGER, Sheldom. The inmate social system. In: CLOWARD, R. et alii (Orgs.). Theoretical studies in social organization of the prison. New York: Social Research Council, 1960.

TELLES, Vera da Silva. A violência como forma de governo. Le Monde Diplomatique Brasil, a.12, n. 139, p. 20-21, 2019.

VIANNA, Adriana. Políticas da morte e seus fantasmas. Le Monde Diplomatique Brasil, a.12, n. 140. p. 20-21, 2019.

WACQUANT, Loïc. O estigma racial na construção do Estado punitivo americano. Configurações, n. 5-6, p. 41-54, 2009.

Punir os pobres: a nova gestão da miséria nos Estados Unidos. Rio de Janeiro: Revan, 2007.

WALTORP, Karen; JENSEN, Steffen. Awkward entanglements: kinship, morality and survival in Cape Town's Prison- township Circuit. Ethnos, v. 84, n. 1, p. 41-55, 2019. 
